\title{
cDNA, genomic sequence cloning and overexpression of giant panda (Ailuropoda melanoleuca) mitochondrial ATP synthase $A$ TP5G1
}

\author{
W.-R. Hou, Y.-L. Hou, X. Ding and T. Wang \\ Key Laboratory of Southwest China Wildlife Resources Conservation, \\ Ministry of Education, College of Life Science, \\ China West Normal University, P.R. China \\ Corresponding author: W.-R Hou \\ E-mail: hwr168@yahoo.com.cn
}

Genet. Mol. Res. 11 (3): 3164-3174 (2012)

Received January 11, 2012

Accepted May 12, 2012

Published September 3, 2012

DOI http://dx.doi.org/10.4238/2012.September.3.5

\begin{abstract}
The ATP5G1 gene is one of the three genes that encode mitochondrialATP synthase subunit c of the proton channel. We cloned the cDNA and determined the genomic sequence of the ATP5G1 gene from the giant panda (Ailuropoda melanoleuca) using RT-PCR technology and touchdown-PCR, respectively. The cloned cDNA fragment contains an open reading frame of $411 \mathrm{bp}$ encoding 136 amino acids; the length of the genomic sequence is of $1838 \mathrm{bp}$, containing three exons and two introns. Alignment analysis revealed that the nucleotide sequence and the deduced protein sequence are highly conserved compared to Homo sapiens, Mus musculus, Rattus norvegicus, Bos taurus, and Sus scrofa. The homologies for nucleotide sequences of the giant panda ATP5G1 to those of these species are 93.92, 92.21, 92.46, 93.67, and 92.46\%, respectively, and the homologies for amino acid sequences are 90.44 , $95.59,93.38,94.12$, and $91.91 \%$, respectively. Topology prediction showed that there is one protein kinase $\mathrm{C}$ phosphorylation site, one
\end{abstract}


casein kinase II phosphorylation site, five N-myristoylation sites, and one ATP synthase c subunit signature in the ATP5G1 protein of the giant panda. The cDNA of ATP5G1 was transfected into Escherichia coli, and the ATP5G1 fused with the N-terminally GST-tagged protein gave rise to accumulation of an expected 40-kDa polypeptide, which had the characteristics of the predicted protein.

Key words: Giant panda; Ailuropoda melanoleuca; ATP5G1; cDNA cloning; Overexpression

\section{INTRODUCTION}

In mammals, the mitochondrial ATP synthase contains 16 different nuclear- or mitochondrial-encoded subunits that are separated into two oligomers. The catalytic $\mathrm{F}_{1}$ oligomer extends into the mitochondrial matrix and is composed of five subunits that form the "headpiece" ( $\alpha$ and $\beta$ subunits) and central stalk ( $\gamma, \delta$, and $\varepsilon$ subunits) (Walker et al., 1985; Abrahams et al., 1994). The Fo oligomer is membrane bound and composed of 10 different subunit types in mammals (a, b, c, d, e, f, g, F6, A6L, OSCP), in which OSCP, F6, b, and d subunits form a peripheral stalk (Walker et al., 1991; Collinson et al., 1994; Carbajo et al., 2005). Mitochondrial ATP synthase subunit c, a highly hydrophobic protein, is one of the chains of the nonenzymatic membrane components that reside in the transmembrane portion of the $\mathrm{F}_{0}$ complex. The ATP5G1 gene is one of the three genes (ATP5G1, ATP5G2, ATP5G3) (Gay and Walker, 1985; Farrell and Nagley, 1987; Higuti et al., 1993a,b), that encode subunit c of the proton channel (Fillingame, 1992). These three different genes, which encoded the c-Fo subunit, are translated into the same mature c subunit protein with different mitochondrial import presequences (Dyer and Walker, 1993; Yan et al., 1994; De Grassi et al., 2006). Of these three isoforms, only the ATP5G1 gene expression is actively regulated in response to various physiological stimuli (such as ontogenic development and cold acclimation), whereas the other isoforms are thought to maintain the basal levels of the c-Fo subunit (Gay and Walker, 1985; Andersson et al., 1997; De Grassi et al., 2006).

The coupled rotation of the subunit $\mathrm{c}$ in $\mathrm{F}_{0}$ appears to be essential for energy coupling between proton transport through $\mathrm{F}_{0}$ and ATP hydrolysis or synthesis in $\mathrm{F}_{1}$ (Sambongi et al., 1999). Therefore, subunit $\mathrm{c}$ is a key component for $\mathrm{F}_{0}$ complex function (Groth, 2000), like an energy-driving motor. The ATP5G1 belongs to the low transcript gene group and its transcriptional regulatory may play a key role in the biogenesis of mammalian $\mathrm{H}^{+}$-ATP synthase (Houstek et al., 1995; Sangawa et al., 1997). It was also found that the protein levels of the ATP5G1 might be crucial for defining the final content of the ATP synthase in brown adipose tissue (Kramarova, 2008). Furthermore, it was reported that the ATP5G1 gene of mouse (Kandil et al., 1997) is closely linked to Psme1 and Psme 2, which have been shown to be highly expressed in lung, spleen and liver tissue in pig (Wang et al., 2004), suggesting that ATP5G1 might be related to animal immunity.

The nuclear genes, ATP5G1, encoding the mitochondrial ATP synthase subunit c, have been cloned in human and other animal species. The giant panda (Ailuropoda melanoleuca) is a rare species currently found only in China. They are known as a "living fossil". For many years, studies on the giant panda have been mainly concentrated on fields such as breeding and propagation, ecology, morphology, taxology, physiology, and pathological biochemistry. Re- 
searches on genetic diversity, parentage and phylogenesis, etc., have been developed (Towbin et al., 1979; Montali, 1990; Wu et al., 1990; Mather et al., 1997; Liao et al., 2003a,b; Du et al., 2007; Hou et al., 2007; Hou et al., 2009). However, the ATP5G1 gene from the giant panda ( $A$. melanoleuca) has not yet been reported.

In the present study, we have amplified the cDNA sequence of the ATP5G1 gene from the total RNAs extracted from the skeleton muscle of the giant panda, and then analyzed the sequence characteristics of the protein encoded by the cDNA and compared it with those of humans and other reported mammalian species. The overexpression was also successfully done in Escherichia coli using pGEX4T-1 plasmids. The study provided scientific data for inquiring into the hereditary traits of the gene from giant panda and formulating the protective strategy for the giant panda.

\section{MATERIAL AND METHODS}

\section{Materials and RNA isolation}

Skeletal muscle was collected from a dead giant panda at the Wolong Conservation Center of the giant panda, Sichuan, China. The collected skeletal muscle was frozen in liquid nitrogen and then used for RNA isolation.

Total RNAs were isolated from about $400 \mathrm{mg}$ muscle tissue using the Total Tissue/ Cell RNA Extraction Kits (Waton Inc., Shanghai, China) according to manufacturer instructions. The total RNAs extracted were dissolved in DEPC (diethylpyrocarbonate) water, and kept at $-70^{\circ} \mathrm{C}$.

\section{Primer design, RT-PCR, cloning of RT-PCR products and sequencing}

The PCR primers were designed by Primer Premier 5.0, based on the mRNA sequence of ATP5G1 from Homo sapiens (NM 001002027), Mus musculus (NM 001161419), Rattus norvegicus (NM 017311), Bos taurus (NM 176649), and Sus scrofa (NM 001025218). The specific primers of ATP5G1 are as follows: $\bar{A} T P 5$ G1-F: 5'-GGGCAGTGGG AGTGCAGACT GA-3'; ATP5G1-R: 3'-CGTTGTGTTTAATGGTAAAGCT-3'.

Total RNAs were synthesized into the first-stranded cDNAs using a reverse transcription kit with Oligo dT as the primers according to manufacturer instructions (Promega, Shanghai, China). The 20-L first-strand cDNA synthesis reaction system included $1 \mathrm{~g}$ total RNAs, 5 $\mathrm{mM} \mathrm{MgCl} 2,1 \mathrm{mM}$ dNTPs, $0.5 \mathrm{~g}$ Oligo dT ${ }_{15}, 10 \mathrm{U} / \mathrm{L}$ RNase inhibitor, and $15 \mathrm{U}$ AMV reverse transcriptase, and was incubated at $42^{\circ} \mathrm{C}$ for $60 \mathrm{~min}$.

The first-strand cDNA synthesized was used as a template. The total reaction volume for DNA amplification was $25 \mu \mathrm{L}$. Reaction mixtures contained $1.5 \mathrm{mM} \mathrm{MgCl}_{2}, 200 \mu \mathrm{M}$ of each dATP, dGTP, dCTP, and dTTP (Omega, China), $0.3 \mu \mathrm{M}$ of each primer, 5.0 U Taq plus DNA polymerase (Sangon Co., Shanghai, China). DNA amplification was performed using an MJ Research thermocycler, Model PTC-200 (Watertown, MA, USA) with a program of $4 \mathrm{~min}$ at $94^{\circ} \mathrm{C}$ followed by 30 cycles of $1 \mathrm{~min}$ at $94^{\circ} \mathrm{C}, 0.5 \mathrm{~min}$ at $45^{\circ} \mathrm{C}$ and $1.5 \mathrm{~min}$ at $72^{\circ} \mathrm{C}$, and then ended with a final extension for $10 \mathrm{~min}$ at $72^{\circ} \mathrm{C}$. After amplification, PCR products were separated by electrophoresis on $1.5 \%$ agarose gel with $1 \mathrm{X}$ TAE (Tris-acetate-EDTA) buffer, stained with ethidium bromide and visualized under UV light. The expected fragments 
of PCR products were harvested and purified from gel using a DNA harvesting kit (Omega), and then ligated into a pMD18T vector (Takara, Japan) at $22^{\circ} \mathrm{C}$ for $12 \mathrm{~h}$. The recombinant molecules were transformed into E. coli complete cells (JM109), and then spread on the LB plate containing $50 \mu \mathrm{g} / \mathrm{mL}$ ampicillin, $200 \mathrm{mg} / \mathrm{mL}$ IPTG (isopropyl-beta-D-thiogalactopyranoside), and $20 \mathrm{mg} / \mathrm{mL} \mathrm{X-gal.} \mathrm{Five} \mathrm{colonies} \mathrm{were} \mathrm{chosen} \mathrm{with} \mathrm{a} \mathrm{vaccination} \mathrm{needle,} \mathrm{extraction}$ plasmid. Plasmid DNA was isolated and digested by PstI and ScaII to verify the insert size. Plasmid DNA was sequenced by Invitrogen (Shanghai, China).

\section{Cloning the genomic sequence of $A T P 5 G 1$}

The PCR primers were the same as the ATP5G1-F and ATP5G1-R presented above. The genomic sequence of the ATP5G1 gene was amplified using touchdown-PCR with the following conditions: $94^{\circ} \mathrm{C}$ for $30 \mathrm{~s}, 62^{\circ} \mathrm{C}$ for $45 \mathrm{~s}, 72^{\circ} \mathrm{C}$ for $4 \mathrm{~min}$ in the first cycle and the annealing temperature decreased $0.5^{\circ} \mathrm{C}$ per cycle; after 20 cycles, conditions changed to $94^{\circ} \mathrm{C}$ for $30 \mathrm{~s}, 52^{\circ} \mathrm{C}$ for $45 \mathrm{~s}, 72^{\circ} \mathrm{C}$ for $4 \mathrm{~min}$ for another 20 cycles. The fragment amplified was also purified, ligated into the clone vector and transformed into E. coli competent cells. Finally, the recombinant fragment was sequenced by Invitrogen.

\section{Construction of the expression vector and overexpression of recombinant ATP5G1}

Based on the sequence of ATP5G1 coding sequences, the primers 5'-CCGGAA TTCAC AATGCAGACCACCG-3' (EcoRI) and 5'-CCGGTCGACGACCCTCACGGAACCT-3' (SalI) were designed to amplify the cDNA (restriction sites are bold and underlined). The PCR was performed at $94^{\circ} \mathrm{C}$ for $3 \mathrm{~min} ; 35$ cycles of $30 \mathrm{~s}$ at $94^{\circ} \mathrm{C}, 45 \mathrm{~s}$ at $53^{\circ} \mathrm{C}$ and $1 \mathrm{~min}$ at $72^{\circ} \mathrm{C}$, and a final extension of $10 \mathrm{~min}$ at $72^{\circ} \mathrm{C}$. The amplified PCR product was cut and ligated into corresponding site of pGEX 4T-1 vector (Stratagen, Shanghai, China). The resulting construct was transformed into E. coli BL21 strain (Novagen, Shanghai, China) and used for the induction by adding IPTG at an $\mathrm{OD}_{600}$ of 0.6 and culturing further for $4 \mathrm{~h}$ at $37^{\circ} \mathrm{C}$ using the empty vector transformed BL21 as a control. The culture was centrifuged at $10,000 \mathrm{~g}$ for $5 \mathrm{~min}$ at room temperature after it was induced for $0.5,1,2,3$, and $4 \mathrm{~h}$, and then separated by SDS-PAGE and stained with Coomassie blue R 250.

After $4 \mathrm{~h}$ of IPTG induction the cell suspension was sonicated in ice-water for a total of 15 min with a microsonicator (Sonics Inc., CA, USA), then the cells were centrifuged at 10,000 g for $30 \mathrm{~min}$ at $4{ }^{\circ} \mathrm{C}$, and the supernatant and pellet treated in lysis buffer containing $6.25 \mathrm{mM}$ Tris$\mathrm{HCl}$, pH 6.8, 2 mM EDTA, 15\% sucrose, 10\% glycerol, 3\% SDS, and $0.7 \mathrm{M} \beta$-mercaptoethanol, were also separated by SDS-PAGE to test the solubility of recombinant ATP5G1.

\section{Data analysis}

The sequence data were analyzed by the GenScan software (http://genes.mit.edu/ GENSCAN.html). Homology research of the giant panda ATP5G1 compared with the gene sequences of other species was performed using Blast 2.1 (http://www.ncbi.nlm.nih.gov/ blast/). ORF of the DNA sequence was searched using the ORF finder software (http://www. ncbi.nlm.nih.gov/gorf/gorf.html). Protein structure of the ATP5G1 sequence cloned was deduced using the PredictProtein software (http://cubic.bioc.columbia.Edu/predictprotein/). 


\section{RESULTS}

\section{Analysis of the cDNA of $A T P 5 G 1$ from the giant panda}

About $500 \mathrm{bp}$ of cDNA fragment was amplified from the giant panda with the primers ATP5G1-F and ATP5G1-R (Figure 1). The length of the cDNA cloned is $530 \mathrm{bp}$. BLAST research showed that the cDNA sequence cloned is highly homologous with the ATP5G1 from H. sapiens (NM_001002027) and some other mammals reported, including M. musculus (NM_001161419), R. norvegicus (NM_017311), B. taurus (NM_176649), and S. scrofa (NM_001025218). On the basis of the high identity, we concluded that the cDNA isolated is the cDNA encoding the giant panda ATP5G1 protein. The ATP5G1 sequence has been submitted to GenBank (accession No. GU338364). An ORF of 411 bp encoding 136 amino acids was found in the cDNA sequence (Figure 2).

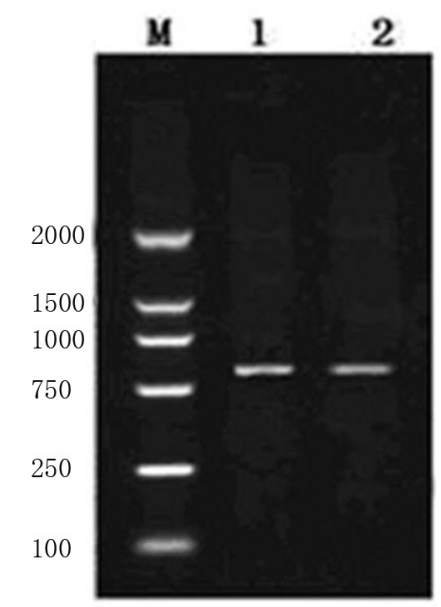

Figure 1. Reverse transcription-polymerase chain reaction products of the giant panda ATP5GI. Lane $M=$ Molecular ladder DL2000; lanes 1 and 2 = amplified ATP5G1.

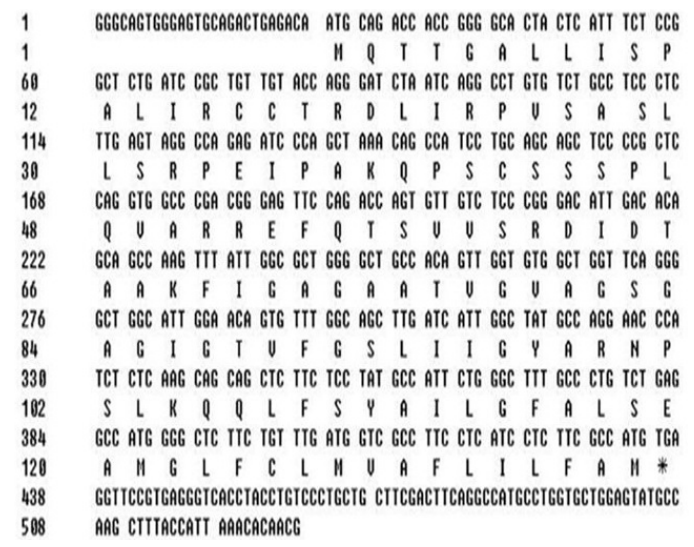

Figure 2. Nucleotide and deduced amino acid sequences of cDNA encoding the giant panda ATP5G1. 


\section{Analysis of the genomic sequence of ATP5G1 from the giant panda}

A fragment of about $1800 \mathrm{bp}$ was amplified from genonic DNA of the giant panda using primers ATP5G1-F and ATP5G1-R (Figure 3). The length of the DNA fragment cloned was $1,838 \mathrm{bp}$. Comparison between the cDNA sequence and this DNA fragment indicated that the cDNA sequence is a full cDNA corresponding to four exons in the the ATP5G1 genomic sequence of the giant panda. The genomic sequence of the ATP5G1 gene has been submitted to GenBank (accession No. GU338365).

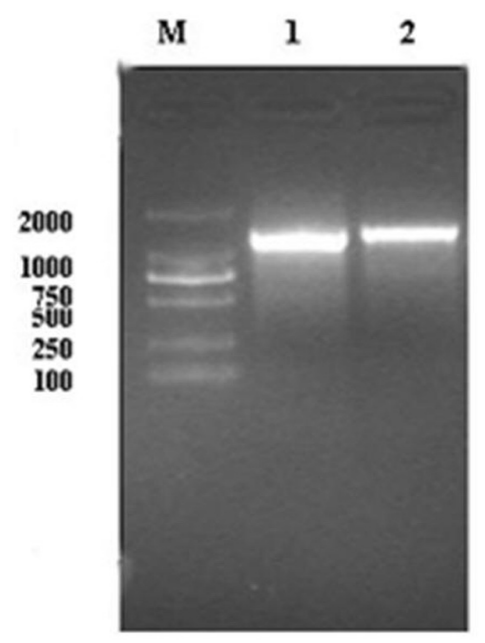

Figure 3. PCR products of complete genomic sequence of the giant panda ATP5G1. Lane $M=$ Molecular ladder DL2000; lanes 1 and 2 amplified ATP5G1 genomic sequences.

\section{Prediction and analysis of protein functional sites in the ATP5G1 protein of the giant panda}

Primary structure analysis revealed that the molecular weight of the putative ATP5G1 protein of the giant panda is $14.2147 \mathrm{kDa}$ with a theoretical $\mathrm{pI}=9.43$ (Table 1). Topology prediction shows there is one protein kinase $\mathrm{C}$ phosphorylation site, one casein kinase II phosphorylation site, five $\mathrm{N}$-myristoylation sites, and one ATP synthase c subunit signature in the ATP5G1 protein of the giant panda (Figure 4).

\section{Overexpression of the ATP5G1 gene in E. coli}

The TP5G1 gene was overexpressed in E. coli and amplified individually by PCR, then cloned in a pGEX 4T-1 plasmid, resulting in a gene fusion coding for a protein bearing a GST-tag extension at the N-terminus. Expression was tested by SDS-PAGE analysis of protein extracts from recombinant in E. coli BL21 (Figure 5).

The results indicated that the protein ATP5G1 fusion with the N-terminally GSTtagged form gave rise to the accumulation of an expected $40-\mathrm{kDa}$ polypeptide that formed 
inclusion bodies. Apparently, the recombinant protein was expressed after half an hour of induction and after $3 \mathrm{~h}$ reached the highest level.

Table 1. Molecular weight and isoelectric point of ATP5G1 of the giant panda (Ailuropoda melanoleuca) and other five mammals.

\begin{tabular}{lcccccc}
\hline & A. melanoleuca & Homus sapiens & Mus musculus & Rattus norvegicus & Bos taurus & Sus scrofa \\
\hline Molecular weight $(\mathrm{kDa})$ & 14.21476 & 14.27673 & 14.19973 & 14.24389 & 14.22266 & 14.21476 \\
Isoelectric point & 9.43 & 9.81 & 10.05 & 9.96 & 9.89 & 9.41 \\
\hline
\end{tabular}

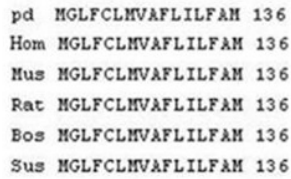

Figure 4. Comparison of the amino acid sequence of ATP5G1 between the giant panda and other five mammalian species. $\mathrm{pd}=$ giant panda; Hom = Homo sapiens; Mus = Mus musculus; Rat $=$ Rattus norvegicus;

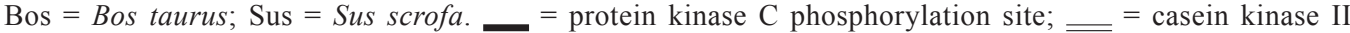
phosphorylation site; $\square=\mathrm{N}$-myristoylation site; $\mathrm{r}_{--}^{--}=\mathrm{N}$-glycosylation site; $\square=\overline{\text { ATP }}$ synthase c subunit signature; $\square=$ cAMP- and cGMP-dependent protein kinase phosphorylation site.

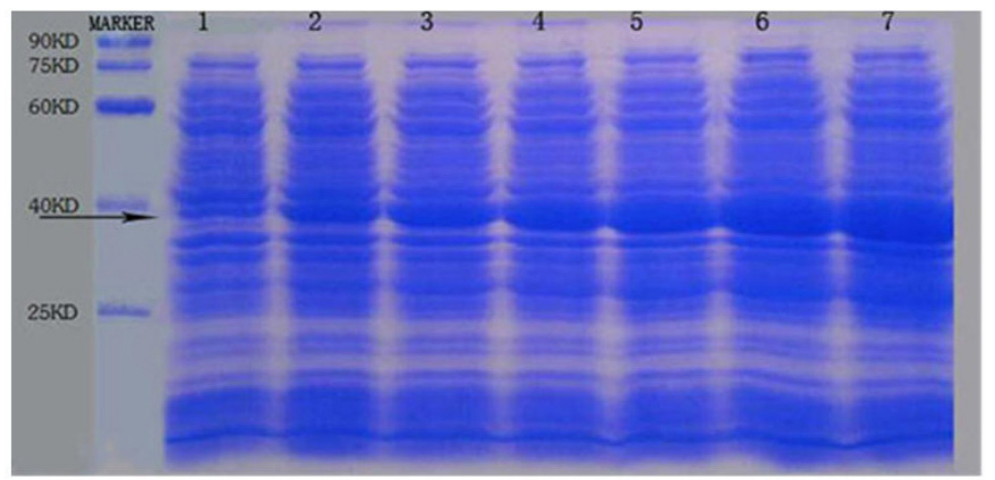

Figure 5. Protein extracted from Escherichia coli BL21 strains were analyzed by SDS-PAGE gel stained with Commassie blue R250. The arrow indicates the recombinant protein bands induced by IPTG at $0,0.5,1,2,3$, and $4 \mathrm{~h}$ (lanes 2-7), respectively. Lane $1=$ Products of the E. coli strains with the empty vectors. 
The supernatant and pellet from the sonicated $E$. coli cells were also tested by SDSPAGE analysis after $4 \mathrm{~h}$ of IPTG induction. The results showed that about $80 \%$ of the recombinant ATP5G1 were soluble and thus can be used to further functional studies.

\section{DISCUSSION}

Alignment analysis of the cDNA sequence of ATP5G1 and the deduced amino acid sequence between the giant panda with other mammals reported, including $H$. sapiens (NM_001002027), M. musculus (NM_001161419), R. norvegicus (NM_017311), B. taurus (NM_176649), and S. scrofa (NM_001025218), was performed by DNĀMAN 6.0. The homologies for coding sequence between the giant panda with the five mammals cited above were 93.92, 92.21, 92.46, 93.67, and 92.64\%, respectively; the homologies for deduced amino acid sequence are $90.44,95.59,93.38,94.12$, and $91.91 \%$, respectively. These results indicated that the coding sequence of ATP5G1 and the deduced amino acid sequence are highly conserved. Further analysis showed that the molecular weight and theoretical $\mathrm{pI}$ of the putative protein of ATP5G1 among its mammalian homologues were very close (Table 1).

The genomic sequence of the ATP5G1 cloned is $1838 \mathrm{bp}$ in size, containing 3 exons and 2 introns. Compared with some mammals, including H. sapiens (NC_000017), M. musculus (NC_000077), R. norvegicus (NC_005109), B. taurus (NC_007317), Pan troglodytes (NC_006484), Macaca mulatta (NC_007873), Canis familiaris (NC_006591), and Gallus gallus (NC_006114), the length of the genomic sequence, number of exons, sites of CDS joined, 5 '- and the 3'-untranslated sequences are different (see Table 2).

\begin{tabular}{|c|c|c|c|c|c|c|c|}
\hline & $\begin{array}{c}\text { Genomic } \\
\text { sequence } \\
\text { length (bp) }\end{array}$ & $\begin{array}{l}\text { Number } \\
\text { of exons }\end{array}$ & $\begin{array}{l}\text { Number } \\
\text { of introns }\end{array}$ & $\begin{array}{c}\text { Length of } \\
\text { 5'-untranslated } \\
\text { sequence (bp) }\end{array}$ & $\begin{array}{c}\text { Length of } \\
\text { 3'-untranslated } \\
\text { sequence (bp) }\end{array}$ & CDS join & $\begin{array}{c}\text { GenBank } \\
\text { accession Nos. }\end{array}$ \\
\hline Ailuropoda melanoleuca & 1838 & 3 & 2 & 26 & 93 & $27 . .65,884 . .961,1452 . .1745$ & GU33836 \\
\hline Homo sapiens & 3086 & 4 & 3 & 632 & 102 & $\begin{array}{l}633 . .671,1587 . .1664 \\
2371 . .2549,2870 . .2984\end{array}$ & NC_000017 \\
\hline Mus musculus & 6186 & 4 & 3 & 13 & 4252 & $\begin{array}{l}13 . .51,999 . .1076 \\
1337 . .1515,1820 . .1934\end{array}$ & NC_000077 \\
\hline Rattus norvegicus & 2581 & 4 & 3 & 565 & 99 & $\begin{array}{l}566 . .604,1531 . .1608 \\
1917 . .2095,2370 . .2484\end{array}$ & NC_005109 \\
\hline Bos taurus & 2124 & 4 & 3 & 40 & 103 & $\begin{array}{l}41 . .79,973 . .1050 \\
1428 . .1606,1907 . .2021\end{array}$ & NC_007317 \\
\hline Pan troglodytes & 3106 & 4 & 3 & 653 & 101 & $\begin{array}{l}654 . .692,1607 . .1684 \\
2419 . .2570,2891 . .3005\end{array}$ & NC_006484 \\
\hline Macaca mulatta & 3044 & 4 & 3 & 629 & 100 & $\begin{array}{l}630 . .668,1573 . .1647 \\
2328 . .2506,2830 . .2944\end{array}$ & NC_007873 \\
\hline Canis familiaris & 2714 & 4 & 3 & 642 & 101 & $\begin{array}{l}643 . .681,1424 . .1501 \\
1980 . .2158,2499 . .2613\end{array}$ & NC_006591 \\
\hline Gallus gallus & 3447 & 4 & 3 & 399 & 371 & $\begin{array}{l}400 . .441,1769 . .1846 \\
2116 . .2291,2962 . .3076\end{array}$ & NC_006114 \\
\hline
\end{tabular}

The deduced protein sequence of ATP5G1 is composed of a signal peptide of 61 amino acids and a mature subunit protein of 75 amino acids (Gay and Walker, 1985; Higuti et al., 1993a,b; Piko et al., 1994). The cDNA of ATP5G1 cloned here is $530 \mathrm{bp}$ in length and contains an open reading frame of $411 \mathrm{bp}$ encoding 136 amino acids. The 5'-noncoding region is $26 \mathrm{bp}$ in length and the 3'-noncoding region consists of 96 nucleotides, excluding the poly (A) tail. 
A polyadenylation signal (ATTAAA), which is common in eukaryotic mRNAs (Wickens and Stephenson, 1984; Fearnley et al., 1990), was located 8 nucleotides upstream from the poly (A) addition site (Figure 4). Part of the poly (A) sequence was present in the 3'-end of this cDNA clone. The mature protein coding region in ATP5G1 is 225 nucleotides long, is capable of encoding a protein of 75 amino acids with a molecular weight of $7.608 \mathrm{kDa}$, and extends from GAC at nucleotide position 210-212 to nucleotide position 434. This coding sequence is followed by the termination codon TGA. Interestingly, the sequence of the mature human subunit $\mathrm{c}$ is completely identical with those of the mature protein of the other five species compared. The possible coding region in ATP5G1 for the import signal peptide is located upstream from the mature protein coding region from only one ATG codon at nucleotide position 27-29 to nucleotide position 209, which is capable of encoding 61 amino acids. In contrast to the mature proteins, the pre-sequences are not conserved.

Our analysis revealed that there is one protein kinase $\mathrm{C}$ phosphorylation site, one casein kinase II phosphorylation site, five N-myristoylation sites, and one ATP synthase c subunit signature in the ATP5G1 protein of the giant panda. It is known that the functional motif (ATP synthase c subunit signature) as well as the highly conserved protein sequences occurring across various species of subunit c play a vital role in maintaining the normal mitochondrial physiological function (Palmer et al., 1989; Li et al., 2001).

In conclusion, the cDNA and the complete coding sequence of the ATP5G1 gene have been cloned and the ATP5G1 cDNA is expressed efficiently in prokaryotic organism using pGEX 4T-1 plasmids. The gained fusion protein is in accordance with the expected 40-kDa polypeptide. These results suggest that the protein is active and is exactly the protein encoded by the ATP5G1 from the giant panda. Further study on the ATP5G1 protein will contribute to the genetic polymorphism and the protection for gene resources of the giant panda.

\section{ACKNOWLEDGMENTS}

Research supported by the Key Chinese National Natural Science Foundation (\#30470261), the Key Discipline Construction Project in Sichuan Province (\#SZD0420), the Key Discipline of Zoology Construction Project in Sichuan Province (\#404001), the Youth Fund Project of Educational Committee of Sichuan Province (\#09ZB088), the Foundation Project of Educational Committee of Sichuan Province (\#10ZC120), and the Application Foundation Projects in Sichuan Province (\#2009JY0061 and \#2011JY0135).

\section{RERERENCES}

Abrahams JP, Leslie AG, Lutter R and Walker JE (1994). Structure at 2.8 A resolution of F1-ATPase from bovine heart mitochondria. Nature 370: 621-628.

Andersson U, Houstek J and Cannon B (1997). ATP synthase subunit c expression: physiological regulation of the P1 and P2 genes. Biochem. J. 323: 379-385.

Carbajo RJ, Kellas FA, Runswick MJ, Montgomery MG, et al. (2005). Structure of the F1-binding domain of the stator of bovine F1Fo-ATPase and how it binds an alpha-subunit. J. Mol. Biol. 351: 824-838.

Collinson IR, Runswick MJ, Buchanan SK, Fearnley IM, et al. (1994). Fo membrane domain of ATP synthase from bovine heart mitochondria: purification, subunit composition, and reconstitution with F1-ATPase. Biochemistry 33: 7971-7978.

De Grassi A, Lanave C and Saccone C (2006). Evolution of ATP synthase subunit $\mathrm{c}$ and cytochrome $\mathrm{c}$ gene families in selected Metazoan classes. Gene 371: 224-233. 
Du YJ, Luo XY, Hao YZ, Zhang T, et al. (2007). cDNA cloning and overexpression of acidic ribosomal phosphoprotein P1 gene (RPLP1) from the giant panda. Int. J. Biol. Sci. 3: 428-433.

Dyer MR and Walker JE (1993). Sequences of members of the human gene family for the c subunit of mitochondrial ATP synthase. Biochem. J. 293: 51-64.

Farrell LB and Nagley P (1987). Human liver cDNA clones encoding proteolipid subunit 9 of the mitochondrial ATPase complex. Biochem. Biophys. Res. Commun. 144: 1257-1264.

Fearnley IM, Walker JE, Martinus RD, Jolly RD, et al. (1990). The sequence of the major protein stored in ovine ceroid lipofuscinosis is identical with that of the dicyclohexylcarbodiimide-reactive proteolipid of mitochondrial ATP synthase. Biochem. J. 268: 751-758.

Fillingame RH (1992). Subunit c of F1F0 ATP synthase: structure and role in transmembrane energy transduction. Biochim. Biophys. Acta 1101: 240-243.

Gay NJ and Walker JE (1985). Two genes encoding the bovine mitochondrial ATP synthase proteolipid specify precursors with different import sequences and are expressed in a tissue-specific manner. EMBO J. 4: 3519-3524.

Groth G (2000). Molecular models of the structural arrangement of subunits and the mechanism of proton translocation in the membrane domain of F(1)F(0) ATP synthase. Biochim. Biophys. Acta 1458: 417-427.

Higuti T, Kuroiwa K, Kawamura Y, Morimoto K, et al. (1993a). Molecular cloning and sequence of cDNAs for the import precursors of oligomycin sensitivity conferring protein, ATPase inhibitor protein, and subunit c of $\mathrm{H}(+)$-ATP synthase in rat mitochondria. Biochim. Biophys. Acta 1172: 311-314.

Higuti T, Kawamura Y, Kuroiwa K, Miyazaki S, et al. (1993b). Molecular cloning and sequence of two cDNAs for human subunit c of $\mathrm{H}(+)-\mathrm{ATP}$ synthase in mitochondria. Biochim. Biophys. Acta 1173: 87-90.

Hou WR, Du YJ, Chen Y, Wu X, et al. (2007). Nucleotide sequence of cDNA encoding the mitochondrial precursor protein of the ATPase inhibitor from the giant panda (Ailuropoda melanoleuca). DNA Cell Biol. 26: 799-802.

Hou YL, Hou WR, Ren ZL, Hao YZ, et al. (2009). cDNA cloning and overexpression of ribosomal protein S19 gene (RPS19) from the giant panda. DNA Cell Biol. 28: 41-47.

Houstek J, Andersson U, Tvrdík P, Nedergaard J, et al. (1995). The expression of subunit c correlates with and thus may limit the biosynthesis of the mitochondrial F0F1-ATPase in brown adipose tissue. J. Biol. Chem. 270: 7689-7694.

Kandil E, Kohda K, Ishibashi T, Tanaka K, et al. (1997). PA28 subunits of the mouse proteasome: primary structures and chromosomal localization of the genes. Immunogenetics 46: 337-344.

Kramarova TV, Shabalina IG, Andersson U, Westerberg R, et al. (2008). Mitochondrial ATP synthase levels in brown adipose tissue are governed by the c-Fo subunit P1 isoform. FASEB J. 22: 55-63.

Li HS, Zhang JY, Thompson BS, Deng XY, et al. (2001). Rat mitochondrial ATP synthase ATP5G3: cloning and upregulation in pancreas after chronic ethanol feeding. Physiol. Genomics 6: 91-98.

Liao MJ, Zhu MY, Zhang ZH, Zhang AJ, et al. (2003a). Cloning and sequence analysis of FSH and LH in the giant panda (Ailuropoda melanoleuca). Anim. Reprod. Sci. 77: 107-116.

Liao MJ, Zhu MY, Zheng X, Zhang ZH, et al. (2003b). cDNA cloning of growth hormone from giant panda (Ailuropoda melanoleuca) and its expression in Escherichia coli. Comp Biochem. Physiol. B Biochem. Mol. Biol. 135: 109-116.

Mather JP, Moore A and Li RH (1997). Activins, inhibins, and follistatins: further thoughts on a growing family of regulators. Proc. Soc. Exp. Biol. Med. 215: 209-222.

Montali RJ (1990). Causes of neonatal mortality in giant panda. Tokyo Zoolog. Park Soc. 83-94.

Palmer DN, Fearnley IM, Medd SM, Walker JE, et al. (1989). Lysosomal storage of the DCCD reactive proteolipid subunit of mitochondrial ATP synthase in human and ovine ceroid lipofuscinoses. Adv. Exp. Med. Biol. 266: 211-222.

Piko L, Nofziger DE, Western LM and Taylor KD (1994). Sequence of a mouse embryo cDNA clone encoding proteolipid subunit 9 (P1) of the mitochondrial H(+)-ATP synthase. Biochim. Biophys. Acta 1184: 139-141.

Sambongi Y, Iko Y, Tanabe M, Omote H, et al. (1999). Mechanical rotation of the c subunit oligomer in ATP synthase (F0F1): direct observation. Science 286: 1722-1724.

Sangawa H, Himeda T, Shibata H and Higuti T (1997). Gene expression of subunit c(P1), subunit c(P2), and oligomycin sensitivity-conferring protein may play a key role in biogenesis of H+-ATP synthase in various rat tissues. J. Biol. Chem. 272: 6034-6037.

Towbin H, Staehelin T and Gordon J (1979). Electrophoretic transfer of proteins from polyacrylamide gels to nitrocellulose sheets: procedure and some applications. Proc. Natl. Acad. Sci. U. S. A. 76: 4350-4354.

Walker JE, Fearnley IM, Gay NJ, Gibson BW, et al. (1985). Primary structure and subunit stoichiometry of F1-ATPase from bovine mitochondria. J. Mol. Biol. 184: 677-701.

Walker JE, Lutter R, Dupuis A and Runswick MJ (1991). Identification of the subunits of F1F0-ATPase from bovine heart mitochondria. Biochemistry 30: 5369-5378.

Wang YF, Yu M, te Pas MF, Yerle M, et al. (2004). Sequence characterization, polymorphism and chromosomal localizations of the porcine PSME1 and PSME2 genes. Anim. Genet. 35: 361-366. 
Wickens M and Stephenson P (1984). Role of the conserved AAUAAA sequence: four AAUAAA point mutants prevent messenger RNA 3' end formation. Science 226: 1045-1051.

Wu ZA, Liu WX, Murphy C and Gall J (1990). Satellite 1 DNA sequence from genomic DNA of the giant panda Ailuropoda melanoleuca. Nucleic Acids Res. 18: 1054.

Yan WL, Lerner TJ, Haines JL and Gusella JF (1994). Sequence analysis and mapping of a novel human mitochondrial ATP synthase subunit 9 cDNA (ATP5G3). Genomics 24: 375-377. 